\title{
A Factor Decomposition on China's Carbon Emission from 1997 to 2012 Based on IPAT-LMDI Model
}

\author{
Wei Li, Ya-Bo Shen, and Hui-Xia Zhang \\ Department of Economic Management, North China Electric Power University, No. 689 Huadian Road, Baoding 071003, China
}

Correspondence should be addressed to Wei Li; ncepulw@126.com

Received 23 January 2015; Accepted 13 May 2015

Academic Editor: Matteo Gaeta

Copyright (C) 2015 Wei Li et al. This is an open access article distributed under the Creative Commons Attribution License, which permits unrestricted use, distribution, and reproduction in any medium, provided the original work is properly cited.

We probe into the key factors that possess significant effects on China's $\mathrm{CO}_{2}$ emissions during 1997-2012 on the basis of IPATLMDI model. Carbon dioxide emissions are specifically decomposed into $\mathrm{CO}_{2}$ emission intensity, energy structure, energy intensity, industrial structure, economic output, and population scale effects. Results indicate that the paramount driving factors that resulted in the growth of $\mathrm{CO}_{2}$ emissions are economic output, population scale, and energy structure. In contrast, energy intensity and industrial structure generally play an outstanding role in reducing emissions. This paper constructs a new weight assessment system by introducing "contribution value-significant factor-effect coefficient" to replace "contribution value-contribution rate" in the previous literature. According to the most significant positive effect and the most negative effect from the conclusion, we point out the effective policies that can not only accelerate the target of "China's carbon emissions per unit of GDP could be cut down by $40-45 \%$ by 2020 , from 2005 levels," but also have crucial significance on the low-carbon economic development strategy of China.

\section{Introduction}

Nowadays, the world economy is in a period of transition to a low-carbon economy, while China is facing a stage of rapid development of industrialization and urbanization. Economic growth gives rise to the augmentation of energy consumption and $\mathrm{CO}_{2}$ emissions [1]. China is the largest developing country in the world with the rapid economic development. China's GDP has increased (from 7225.34 to 29533.57 billion Yuan) sharply at the average annual rate of 9.84\%, and the per capita GDP has increased (from 5873.91 to 21865.47 Yuan) dramatically at the average annual rate of $9.16 \%$ [2]. The total GDP has run up to 5878.61 billion dollars by 2010 exceeding Japan, turning into the second largest economy in the world. At the same time, China's primary energy consumption raised sharply from 1.38 to 3.62 billion ton coal equivalent (tec) during 1997-2012 [2]. With the persistent focus on climate change from all countries in the world, carbon emissions have captured growing attention of our government. China's carbon emissions keep on rising fleetly with relevant energy consumption level, from 3528.02 million tons in 1997 to 9774.47 million tons in 2012. China's energy-related carbon emissions have reached 7.03 billion tons by 2008, surpassing the United States to become the world's largest emitter for the first time. That makes China's international pressure increase in response to climate change issues. China possesses an ambitious goal to reduce carbon emissions intensity by $40-45 \%$ of the 2005 level by 2020 . Carbon emissions will constraint China's energy consumption in the process of the increased economy.

The IPAT identity was first proposed by Professors Ehrlich and Holdren to depict the influence on the environment of growing population [3, 4]. Nakicenovic used a reformulation of this IPAT identity known as the Kaya equation to be the basis for the GHG emissions calculations, projections, and scenarios conducted by the Intergovernmental Panel on Climate Change [5]. Two main methods are used for decomposition of carbon emission factors: structural decomposition analysis (SDA) and index decomposition analysis (IDA) [6,7]. In recent years, many scholars have done multitude research on carbon emissions with the SDA and they found a host of practical significant conclusions [8-11]. Ang put forward the log Mean Divisia Index in the first place [12]. The log Mean Divisia Index (LMDI) can not only be used to decompose multiple factors with zero residual errors, but it can also be used to solve the problem of insufficient 
data. With this method, carbon emissions can be resolved quantitatively into several effects $[13,14]$. Ang and Wang et al. came to the conclusion by using the LMDI method that economic growth is a leading cause of carbon emissions and energy intensity is seen as essential effect if China's carbon emissions are looked forward to being reduced over the long term $[15,16]$. Chunbo, Tunc, and Claudia explained the primary element affecting the change of China's carbon emissions. Turkey and Mexico applied the LMDI approach to decompose carbon emissions [17-19]. Paul and Bhattacharya pointed out that energy intensity, industrial structure, the change of GDP, and emissions from several types of fossil fuels were four effects affecting carbon emissions in India [20]. Sun worked out the differences in carbon emissions intensity from Sweden and Finland [21]. Choi and Ang used the index decomposition methods to analyze carbon emissions from energy consumption [22]. Factors of carbon emission in Turkey were decomposed by Ipek Tunç et al. into economic growth effect, industrial structure effect, energy sources effect, energy efficiency effect, and carbon emission coefficient effect [23]. It is also suitable to study China's energy-related carbon emission by applying the completed decomposition technique [24-29]. Li and Ou analyzed the influence factors of carbon emission intensity in China during 1995-2010 by using the modified LMDI (Kaya) model and obtained that the most crucial negative factor affecting carbon emissions intensity was energy intensity effect [30]. Liu et al. made the decomposition on carbon emission factors for 36 Chinese industrial sectors from 1998 to 2005 by the LMDI method and reached that energy intensity was the topdrawer factor leading to carbon emissions changes [31]. Xu et al. researched factors affecting carbon emissions during 1995-2011 by using LMDI theory and found that the energy intensity was the most paramount inhibitory factor [32]. Wei et al. and $\mathrm{Wu}$ et al. pointed to the most significant conclusion on some general information for carbon emissions and the fundamental driving factors [33, 34]. Previous studies have demonstrated that energy-related carbon emissions in China increased significantly in the literature. For example, the growth of cement output largely promotes the energy consumption leading to the increase of carbon emissions in the cement industry. Coal products have been the dominant fuel for thermal power generation and the economic activity effect is the major driving force in carbon emissions in electricity. Residential energy consumption (REC) is China's second-largest energy use category. China's price reform in the field of energy plays a key role in reducing REC. Besides, there is bidirectional causality between carbon emissions and energy consumption based on the panel data, and so do energy consumption and economic growth. According to the studies, some important policies of the empirical results have been put forward in the literature. In contrast, few studies depict the factors affecting carbon emissions from different industries and different species of energy with data.

This study analyzed the influencing factors of $\mathrm{CO}_{2}$ emissions from eight kinds of energy (coal, coke, crude oil, gasoline, kerosene, diesel oil, fuel oil, and natural gas) in eight industries sectors (excavation; manufacturing; electric power, gas, and water production and supply; agriculture; construction; transportation, storage, and postal services; wholesale, retail trade, and food services; and other sectors). It is more accurate to decompose $\mathrm{CO}_{2}$ emissions in every single industry according to the segmentation of carbon dioxide emission coefficient. Then, we probed factors affecting the growth of $\mathrm{CO}_{2}$ emissions owing to China's energy consumption based on the LMDI model. Most importantly, the method of "contribution value-significant factor-effect coefficient" makes up the deficiency in the concept and algorithm. Besides, we explored the relative effect size of each effect coefficient and gained the most significant positive effect and the most negative effect, making it easier for the government to draw up an array of targeted measures and policy adjustment. However, the inadequacy of this method of effect coefficient may be the case that the contribution value of each effect is 0 . In addition, a few shortcomings remain possible in the paper. For $\mathrm{CO}_{2}$ emissions, coefficient remains the same, so that $\mathrm{CO}_{2}$ emission intensity effects are considered zero from the results, and this makes how to decompose the effect size be the research direction in the future. Based on the empirical study, we obtain the relative effect size of each factor on $\mathrm{CO}_{2}$ emissions and put forward a slice of practical policy. These will have the important practical significance on the realization of emission reduction targets and the further development of low-carbon economy.

\section{Decomposition Methodology}

2.1. IPAT Model. The IPAT accounting model, first proposed by Professors Ehrlich and Holdren in the early 1970s, is a widely applied model to express the impact on environment of economic development $[3,4]$. In other words, the environmental problem is the integrated impact of population, economy, and technology. The basic equation of IPAT model can be stated as follows:

$$
I=P \times A \times T,
$$

where $I$ denotes environment load; $P$ is population; $A$ is GDP per capita, namely, richness degree; and $T$ is environmental load per unit of GDP, that is technology level. The environmental impact equation into the IPAT model of carbon emissions is equivalent to the Kaya model as follows:

$$
\mathrm{CO}_{2}=P \times \frac{\mathrm{GDP}}{P} \times \frac{E}{\mathrm{GDP}} \times \frac{\mathrm{CO}_{2}}{E},
$$

where GDP/P denotes richness degree; $E / G D P$ is energy intensity, mostly concerned with technology; $\mathrm{CO}_{2} / E$ is carbon emissions intensity, mostly concerned with energy structure.

According to the relevant knowledge of calculus, (2) can be transformed into the following equation:

$$
\begin{aligned}
d\left(\ln \mathrm{CO}_{2}\right)= & d(\ln P)+d\left(\ln \frac{\mathrm{GDP}}{P}\right)+d\left(\ln \frac{E}{\mathrm{GDP}}\right) \\
& +d\left(\ln \frac{\mathrm{CO}_{2}}{E}\right) .
\end{aligned}
$$

This paper verifies China's energy-related carbon emissions changes from 1997 to 2012 by formula (3). The average 
annual rate about each parameter on the right of the formula is shown as follows:

$$
\begin{aligned}
d(\ln P) & =0.63 \%, \\
d\left(\ln \frac{\mathrm{GDP}}{P}\right) & =9.16 \%, \\
d\left(\ln \frac{E}{\mathrm{GDP}}\right) & =-2.77 \%, \\
d\left(\ln \frac{\mathrm{CO}_{2}}{E}\right) & =0.21 \% .
\end{aligned}
$$

Therefore,

$$
\begin{aligned}
d\left(\ln \mathrm{CO}_{2}\right) & =0.63 \%+9.16 \%-2.77 \%+0.21 \% \\
& =6.81 \%
\end{aligned}
$$

However, the average annual rate of carbon emissions according to real statistic increased by $7.03 \%$ is approximately $0.22 \%$ of the residuals. We can see that the equation of the Kaya decomposition appeared residual. That is, it caused unbalance at both sides of the equation. Lead, once again, to an inadequate explanation for the change of carbon emissions.

In this paper, China's energy-related $\mathrm{CO}_{2}$ emissions is decomposed into $\mathrm{CO}_{2}$ emissions intensity effect, energy structure effect, energy intensity effect, industrial structure effect, economic output effect (per capita GDP), and population effect based on the equation of energy-related carbon emissions as follows:

$$
C=\sum_{i, j} C_{i, j}=\sum_{i, j} \frac{C_{i, j}}{E_{i, j}} \times \frac{E_{i, j}}{E_{i}} \times \frac{E_{i}}{Q_{i}} \times \frac{Q_{i}}{Q} \times \frac{Q}{P} \times P .
$$

The following variables appeared in the above equation.

$C$ is the total $\mathrm{CO}_{2}$ emissions.

$C_{i, j}$ is $\mathrm{CO}_{2}$ emissions from consumption of fossil fuel $j$ in sector $i$.

$E_{i, j}$ is energy consumption from fossil fuel $j$ in sector $i$.

$E_{i}$ is total energy consumption in sector $i$.

$Q_{i}$ is the GDP output of sector $i$.

$Q$ is GDP.

$P$ is population.

The carbon dioxide emissions utilizing this method can be rewritten as follows:

$$
C=\sum_{i, j} C_{i, j}=\sum_{i, j} F_{i, j} \times M_{i, j} \times R_{i} \times H \times Y \times P .
$$

The following definition is adopted within the above magnitude.

$F_{i, j}=C_{i, j} / E_{i, j}$ is the $\mathrm{CO}_{2}$ emissions coefficient.

$M_{i, j}=E_{i, j} / E_{i}$ is the share of fossil fuel $j$ over the total fossil fuels in sector $i$, namely, energy structure effect.
$R_{i}=E_{i} / Q_{i}$ is energy intensity in sector $i$, namely, energy intensity effect.

$H=Q_{i} / Q$ is the proportion of economic output in sector $i$ over the total industrial output, namely, industrial structure effect.

$Y=Q / P$ is per capita GDP, that is, economic output effect.

$P$ is population effect.

2.2. On the Decomposition of Carbon Emissions by LMDI. Logarithmic Mean Divisia Index (LMDI II) is a method which is used to decompose $\mathrm{CO}_{2}$ emissions factors in this research. The following equation indicates the changes in carbon emissions from year 0 to year $T$ :

$$
\begin{aligned}
\Delta C & =C^{T}-C^{0} \\
& =\Delta C_{F}+\Delta C_{M}+\Delta C_{R}+\Delta C_{H}+\Delta C_{Y}+\Delta C_{P},
\end{aligned}
$$

where $\Delta C$ represents the total $\mathrm{CO}_{2}$ emissions change; $\Delta C_{F}$ represents $\mathrm{CO}_{2}$ emissions intensity; $\Delta C_{M}$ represents energy structure effect; $\Delta C_{R}$ represents energy intensity effect; $\Delta C_{H}$ represents industrial structure effect; $\Delta C_{Y}$ represents economic output effect; and $\Delta C_{P}$ represents population effect. 0 and $T$ represent the base year and the target year. According to Logarithmic Mean Divisia Index theory [12-14], the decomposition results are shown as follows:

$$
\begin{aligned}
\Delta C_{F} & =\sum_{i=1}^{8} \sum_{j=1}^{8}\left[L\left(C_{i, j}^{T}, C_{i, j}^{0}\right) \times \ln \frac{F_{i, j}^{T}}{F_{i, j}^{0}}\right], \\
\Delta C_{M} & =\sum_{i=1}^{8} \sum_{j=1}^{8}\left[L\left(C_{i, j}^{T}, C_{i, j}^{0}\right) \times \ln \frac{M_{i, j}^{T}}{M_{i, j}^{0}}\right], \\
\Delta C_{R}= & \sum_{i=1}^{8} \sum_{j=1}^{8}\left[L\left(C_{i, j}^{T}, C_{i, j}^{0}\right) \times \ln \frac{R_{i}^{T}}{R_{i}^{0}}\right], \\
\Delta C_{H}= & \sum_{i=1}^{8} \sum_{j=1}^{8}\left[L\left(C_{i, j}^{T}, C_{i, j}^{0}\right) \times \ln \frac{H^{T}}{H^{0}}\right], \\
\Delta C_{Y}= & \sum_{i=1}^{8} \sum_{j=1}^{8}\left[L\left(C_{i, j}^{T}, C_{i, j}^{0}\right) \times \ln \frac{Y^{T}}{Y^{0}}\right], \\
\Delta C_{P}= & \sum_{i=1}^{8} \sum_{j=1}^{8}\left[L\left(C_{i, j}^{T}, C_{i, j}^{0}\right) \times \ln \frac{P^{T}}{P^{0}}\right] .
\end{aligned}
$$

We define

$$
L\left(C_{i, j}^{T}, C_{i, j}^{0}\right)= \begin{cases}\frac{C_{i, j}^{T}-C_{i, j}^{0}}{\ln C_{i, j}^{T}-\ln C_{i, j}^{0}} & C_{i, j}^{T} \neq C_{i, j}^{0} \\ C_{i, j}^{T} & C_{i, j}^{T}=C_{i, j}^{0} .\end{cases}
$$

At the same time, $F \neq 0, M \neq 0, R \neq 0, H \neq 0, Y \neq 0$, $P \neq 0$.

Since the $\mathrm{CO}_{2}$ emissions coefficients of various types of fossil fuels remaining the same, $\Delta C_{F}$ is zero. 
The lack of LMDI model, being applied to make the factor decomposition based on the existing references, is the disunity from each impact factor of weighting algorithm, the insufficiency on significance of the positive and negative effects, and the defects of the existing algorithms on "contribution rate." The specific calculation methods of "contribution rate" can be divided into two kinds: one kind is to use contribution rate of each factor divided by the sum of all factors, getting the "contribution rate" lack of discrimination. Another is to calculate the proportion of each positive (negative) contribution value in all by wielding separately the positive (negative) contribution value, getting the distinction between "positive contribution rate" and "negative contribution rate." In this paper, the use of the unique algorithm which created "contribution value-significant factor-effect coefficient" to substitute "contribution value-contribution rate" in the former documents overcame the defect of the existing method. This method is suitable in case that the total contribution value of each effect is negative even for the special case of 0 . So, a significant comparative research on all influence factors was conducted in this paper to figure out the most significant positive effect and the most negative effect.

The significant factor refers to the ratio of the absolute value of each effect contribution value over the sum of absolute values of each effect contribution value, recording $\zeta$. The greater the significant factor (the maximum value is 1 ), the more the effect on carbon emissions from the same factor; namely, the effect is more obvious. The smaller the significant factor (the minimum value is 0 ), the less the effect on carbon emissions from the same factor; namely, the effect is more weak. The definition of each significant factor is shown as follows:

$$
\begin{aligned}
& \zeta_{F} \\
& =\frac{\left|\Delta C_{F}\right|}{\left|\Delta C_{F}\right|+\left|\Delta C_{M}\right|+\left|\Delta C_{R}\right|+\left|\Delta C_{H}\right|+\left|\Delta C_{Y}\right|+\left|\Delta C_{P}\right|}, \\
& \zeta_{M} \\
& =\frac{\left|\Delta C_{M}\right|}{\left|\Delta C_{F}\right|+\left|\Delta C_{M}\right|+\left|\Delta C_{R}\right|+\left|\Delta C_{H}\right|+\left|\Delta C_{Y}\right|+\left|\Delta C_{P}\right|}, \\
& \zeta_{R} \\
& =\frac{\left|\Delta C_{R}\right|}{\left|\Delta C_{F}\right|+\left|\Delta C_{M}\right|+\left|\Delta C_{R}\right|+\left|\Delta C_{H}\right|+\left|\Delta C_{Y}\right|+\left|\Delta C_{P}\right|}, \\
& \zeta_{H} \\
& \quad=\frac{\left|\Delta C_{H}\right|}{\left|\Delta C_{F}\right|+\left|\Delta C_{M}\right|+\left|\Delta C_{R}\right|+\left|\Delta C_{H}\right|+\left|\Delta C_{Y}\right|+\left|\Delta C_{P}\right|}, \\
& \zeta_{Y} \\
& \quad=\frac{\left|\Delta C_{Y}\right|}{\left|\Delta C_{F}\right|+\left|\Delta C_{M}\right|+\left|\Delta C_{R}\right|+\left|\Delta C_{H}\right|+\left|\Delta C_{Y}\right|+\left|\Delta C_{P}\right|}, \\
& \zeta_{P} \\
& \quad \frac{\left|\Delta C_{F}\right|+\left|\Delta C_{M}\right|+\left|\Delta C_{R}\right|+\left|\Delta C_{H}\right|+\left|\Delta C_{Y}\right|+\left|\Delta C_{P}\right|}{\mid}
\end{aligned}
$$

The significant factor denotes the effect size, relatively. It can not explain its impact properties. Therefore, we introduce a new index called the effect coefficient to consider the influence of specific properties synthetically. Effect coefficient refers to the product between each effect coefficient and the sign of the effect of contribution value, recording $e$. Effect coefficient, with the sign of positive, indicates that the effect has a positive effect on carbon emissions, called the positive effect. In contrast, we called it the negative effect.

The minus of the effect of contribution value needs to be extracted when counting the effect coefficient, so we draw into the following sign function:

$$
\operatorname{Sgn}(x)= \begin{cases}1, & x>0 \\ 0, & x=0 \\ -1, & x<0\end{cases}
$$

Effect coefficient of each effect is as follows:

$$
\begin{aligned}
& e_{F}=\operatorname{Sgn}\left(\Delta C_{F}\right) \cdot \zeta_{F}, \\
& e_{M}=\operatorname{Sgn}\left(\Delta C_{M}\right) \cdot \zeta_{M}, \\
& e_{R}=\operatorname{Sgn}\left(\Delta C_{R}\right) \cdot \zeta_{R}, \\
& e_{H}=\operatorname{Sgn}\left(\Delta C_{H}\right) \cdot \zeta_{H}, \\
& e_{Y}=\operatorname{Sgn}\left(\Delta C_{Y}\right) \cdot \zeta_{Y}, \\
& e_{P}=\operatorname{Sgn}\left(\Delta C_{P}\right) \cdot \zeta_{P} .
\end{aligned}
$$

Because $\operatorname{Sgn}(x) \cdot|x| \equiv x$ is constant for any variable $x$, the effect coefficient of each effect can be expressed as

$$
\begin{aligned}
& e_{F} \\
& =\frac{\Delta C_{F}}{\left|\Delta C_{F}\right|+\left|\Delta C_{M}\right|+\left|\Delta C_{R}\right|+\left|\Delta C_{H}\right|+\left|\Delta C_{Y}\right|+\left|\Delta C_{P}\right|}, \\
& e_{M} \\
& =\frac{\Delta C_{M}}{\left|\Delta C_{F}\right|+\left|\Delta C_{M}\right|+\left|\Delta C_{R}\right|+\left|\Delta C_{H}\right|+\left|\Delta C_{Y}\right|+\left|\Delta C_{P}\right|}, \\
& e_{R} \\
& =\frac{\Delta C_{R}}{\left|\Delta C_{F}\right|+\left|\Delta C_{M}\right|+\left|\Delta C_{R}\right|+\left|\Delta C_{H}\right|+\left|\Delta C_{Y}\right|+\left|\Delta C_{P}\right|}, \\
& e_{H} \\
& =\frac{\Delta C_{H}}{\left|\Delta C_{F}\right|+\left|\Delta C_{M}\right|+\left|\Delta C_{R}\right|+\left|\Delta C_{H}\right|+\left|\Delta C_{Y}\right|+\left|\Delta C_{P}\right|}, \\
& e_{Y} \\
& =\frac{\Delta C_{Y}}{\left|\Delta C_{F}\right|+\left|\Delta C_{M}\right|+\left|\Delta C_{R}\right|+\left|\Delta C_{H}\right|+\left|\Delta C_{Y}\right|+\left|\Delta C_{P}\right|}
\end{aligned}
$$




$$
\begin{aligned}
& e_{P} \\
& =\frac{\Delta C_{P}}{\left|\Delta C_{F}\right|+\left|\Delta C_{M}\right|+\left|\Delta C_{R}\right|+\left|\Delta C_{H}\right|+\left|\Delta C_{Y}\right|+\left|\Delta C_{P}\right|} .
\end{aligned}
$$

The formulas (14) stand for the effect coefficient of each factor on carbon emissions. These formulas can clearly reflect the extent of influence and the characteristics of impact. The positive effect coefficient shows that the effect can promote the increase of carbon emissions. On the contrary, the negative effect coefficient indicates the inhibition of carbon emissions.

\section{Date and Analysis}

3.1. Sources of Data. This paper chose the period from 1997 to 2012 to make the factor decomposition on China's carbon emission, considering that a legally binding Kyoto Protocol was signed in 1997, setting the mandatory emissions targets for the first time. China subsequently joined in WTO in 2001, carbon emission drastically increase with the rapid economic growth in the next few years. The government proposed that the target of "Carbon emissions per unit of GDP could be cut down by $17 \%$ by 2015, from 2010 levels." The change of policy after 2012 would greatly affect the trend of carbon emissions. To highlight the degree of influence of each effect at these tipping points, we employed the data during 1997-2012. In addition, the data sources could support longer period for the study based on the accessibility and authenticity of data.

This paper draws up a detailed analysis of the economic output and the energy consumption in all sectors (excavation; manufacturing; electric power, gas, and water production and supply; agriculture; construction; transportation, storage, and postal services; wholesale, retail trade, and food services; other sectors). The part mainly analyzes the energy consumption of coal, coke, crude oil, gasoline, kerosene, diesel oil, fuel oil, and natural gas. This research employed annual data of GDP and population and energy consumption from China Statistical Yearbook [1]. GDP and the economic output (billion Yuan) are transformed to unified standard prices for the base period of 1997. The population data are calculated with the average from the end of the adjacent two years. The energy consumption of all departments is transformed into ton coal equivalent (tec) based on Intergovernmental Panel on Climate Change (IPCC) [35]. The energy consumption unit is defined as million tons of standard coal and carbon emissions are set at millions of tons.

Because the data involved range during the calculation of $\mathrm{CO}_{2}$ is wide, normally the compilation of emission inventory is conducted by the government and research institutions. Currently, there are massive ways of compiling emission inventory, yet no unified and authoritative method has been formed, especially the research on oxidation coefficient of different fuels. This paper referred to a slice of methods provided from researches of IPCC and other scholars and then improved the calculation method of carbon emissions by subdividing the carbon emissions coefficient. With the improved method, we calculated the carbon emissions

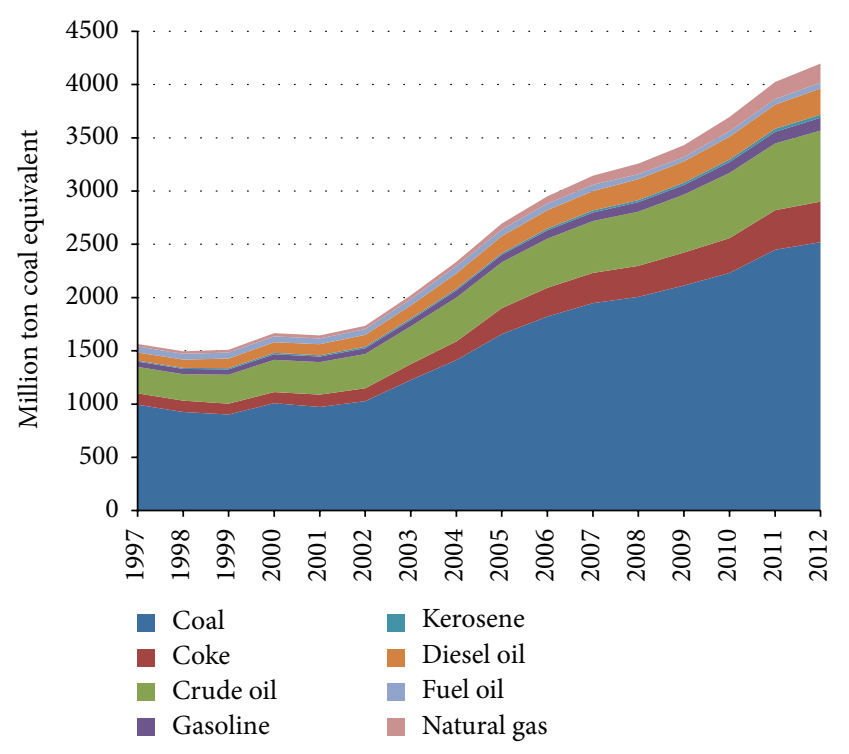

Figure 1: Energy consumption in China from 1997 to 2012.

of energy consumption in eight sectors and obtained the energy-related carbon emissions from 1997 to 2012.

The specific calculation formulas are shown as follows:

$$
\begin{aligned}
C & =\sum_{i, j} C_{i, j}=\sum_{i=1}^{8} \sum_{j=1}^{8} E_{i, j} \times K_{i, j}, \\
K_{i, j} & =Q_{j} \times N_{j} \times O_{i, j},
\end{aligned}
$$

where $C_{i, j}$ denotes $\mathrm{CO}_{2}$ emissions from consumption of fossil fuel $j$ in sector $i, E_{i, j}$ denotes energy consumption of fossil fuel $j$ in sector $i, K_{i, j}$ denotes $\mathrm{CO}_{2}$ emissions coefficient of fossil fuel $j$ in sector $i, Q_{j}$ denotes the average net calorific value, $N_{j}$ denotes carbon emissions factor of fossil fuel $j$, and $O_{i, j}$ denotes carbon oxidation coefficient of fossil fuel $j$ in sector $i$.

3.2. Analysis of Data. The results of energy-related $\mathrm{CO}_{2}$ emissions coefficient according to the improved method are shown in Table 1. Energy consumption and $\mathrm{CO}_{2}$ emissions from each department during 1997-2012 are shown in Tables 2 and 3.

Energy activity is an important source of carbon emissions in China. The phenomenon on the incomplete combustion of energy occurs frequently in the process of burning. Thus, besides considering the emission factors of the whole energy, we need to consider the coefficient of oxidation of all energy. Table 1 indicates carbon emissions coefficient of energy in each department. It will be a more precise way to solve energy-related carbon emissions with the segmentation of carbon emissions coefficient.

Figure 1 demonstrates the various kinds of energy consumption from 1997 to 2012. Figure 3 demonstrates industrial energy consumption, the total energy consumption, and energy-related $\mathrm{CO}_{2}$ emissions. As shown in Figure 3, the trend of energy-related $\mathrm{CO}_{2}$ emissions in the industry is broadly in line with the total $\mathrm{CO}_{2}$ emissions. There is 
TABLE 1: Carbon dioxide emission coefficient for various departments (unit: $\mathrm{KgCO}_{2} / \mathrm{Kg}$ ).

\begin{tabular}{|c|c|c|c|c|c|c|c|c|}
\hline Year & Excavation & Manufacturing & $\begin{array}{l}\text { Electric power, } \\
\text { gas, and water } \\
\text { production and } \\
\text { supply }\end{array}$ & Agriculture & Construction & $\begin{array}{l}\text { Transportation, } \\
\text { storage, and } \\
\text { postal services }\end{array}$ & $\begin{array}{l}\text { Wholesale, retail } \\
\text { trade, and food } \\
\text { services }\end{array}$ & Other \\
\hline Coal & 1.7781 & 1.7781 & 1.7781 & 1.5823 & 1.5823 & 1.5823 & 1.5823 & 1.7781 \\
\hline Coke & 2.9513 & 2.9513 & 2.9513 & 2.9513 & 2.9513 & 2.9513 & 2.9513 & 2.9513 \\
\hline Crude oil & 3.0038 & 3.0038 & 3.0038 & 3.0038 & 3.0038 & 3.0038 & 3.0038 & 3.0038 \\
\hline Gasoline & 2.9251 & 2.9251 & 2.9251 & 2.9251 & 2.9251 & 2.9251 & 2.9251 & 2.9251 \\
\hline Kerosene & 3.0179 & 3.0179 & 3.0179 & 3.0179 & 3.0179 & 3.0179 & 3.0179 & 3.0179 \\
\hline Diesel oil & 3.0973 & 3.0973 & 3.0973 & 3.0973 & 3.0973 & 3.0973 & 3.0973 & 3.0973 \\
\hline Fuel oil & 3.1683 & 3.1683 & 3.1683 & 3.1683 & 3.1683 & 3.1683 & 3.1683 & 3.1683 \\
\hline Natural gas & 21.6219 & 21.6219 & 21.6219 & 21.6219 & 21.6219 & 21.6219 & 21.6219 & 21.6219 \\
\hline
\end{tabular}

TABle 2: Annual time series of energy consumption in China from 1997 to 2012 (unit: Mtce).

\begin{tabular}{lcccccccc}
\hline Year & Coal & Coke & Crude oil & Gasoline & Kerosene & Diesel oil & Fuel oil & Natural gas \\
\hline 1997 & 994.65 & 106.14 & 248.11 & 48.73 & 10.03 & 77.10 & 54.98 & 24.02 \\
1998 & 924.96 & 107.61 & 248.51 & 48.98 & 9.88 & 76.97 & 54.70 & 24.90 \\
1999 & 902.63 & 101.58 & 270.71 & 49.74 & 12.13 & 90.80 & 56.20 & 26.42 \\
2000 & 1007.82 & 105.31 & 303.32 & 51.57 & 12.82 & 99.17 & 55.33 & 30.12 \\
2001 & 972.29 & 115.90 & 304.90 & 52.93 & 12.00 & 104.30 & 55.00 & 28.54 \\
2002 & 1027.66 & 119.91 & 322.06 & 55.17 & 12.93 & 111.71 & 55.34 & 30.19 \\
2003 & 1225.61 & 148.61 & 356.04 & 59.92 & 13.03 & 122.53 & 60.29 & 35.30 \\
2004 & 1412.84 & 175.50 & 410.71 & 69.09 & 15.21 & 144.19 & 68.34 \\
2005 & 1656.11 & 243.88 & 429.81 & 71.43 & 15.84 & 159.88 & 60.60 & 40.50 \\
2006 & 1821.93 & 270.95 & 460.65 & 77.14 & 16.55 & 172.45 & 62.41 & 57.47 \\
2007 & 1948.22 & 283.34 & 486.18 & 81.21 & 18.30 & 182.09 & 59.39 & 89.00 \\
2008 & 2007.87 & 290.45 & 507.13 & 90.43 & 19.04 & 197.18 & 46.25 \\
2009 & 2113.14 & 309.39 & 544.71 & 90.82 & 21.18 & 200.45 & 40.40 & 99.91 \\
2010 & 2230.31 & 327.24 & 612.51 & 101.32 & 25.66 & 213.23 & 53.69 & 110.02 \\
2011 & 2449.69 & 370.72 & 628.10 & 108.82 & 26.73 & 227.82 & 52.33 \\
2012 & 2518.96 & 382.47 & 666.86 & 119.79 & 28.79 & 247.21 & 52.62 & 131.43 \\
\hline
\end{tabular}

a continued gently rising trend of energy consumption during 1997-2002 and 2006-2010, and so do $\mathrm{CO}_{2}$ emissions. During 2002-2006, energy consumption increased rapidly along with $\mathrm{CO}_{2}$ emissions corresponding to the rapid rise. Energy consumption has a fast-growing trend during 2010-2012 too. The total energy consumption increased at an average annual rate of $6.80 \%$ (from 1563.76 to 4196.49 million tons), and $\mathrm{CO}_{2}$ emissions were raised at an average annual rate of $7.03 \%$ (from 3528.02 to 9774.47 million tons) during 1997-2012. China's primary energy consumption grew from 1381.73 million tons to 3617.32 million tons. The ratio of coal (coal and coke) over the total energy consumption gently reduced from $70.39 \%$ to $69.12 \%$, the proportion of oil (crude oil, gasoline, kerosene, diesel oil, and fuel oil) decreased from $28.07 \%$ to $26.58 \%$, and the ratio of natural gas sharply increased from $1.58 \%$ to $4.32 \%$. Despite the fact that the consumption of natural gas accounts for the proportion increases year by year, coal consumption has been the main energy consumption (the proportion is about $70 \%$ ). Therefore, $\mathrm{CO}_{2}$ emissions are mainly caused by the consumption of coal. This makes the control of coal become the main way to reduce $\mathrm{CO}_{2}$ emissions.
Figure 2 demonstrates energy-related $\mathrm{CO}_{2}$ emissions in the eight sectors from 1997 to 2012. As shown in the chart, because of the rapid development of manufacturing industry and electric power, gas, and water production and supply industry, $\mathrm{CO}_{2}$ emissions from manufacturing industry which is the largest sector of $\mathrm{CO}_{2}$ emissions account for more than $50 \%$ of total $\mathrm{CO}_{2}$ emissions, exceeding the ratio over $30 \%$ from electric power, gas, and water production and supply industry. The transportation industry accounts for about $5 \%$.

Carbon dioxide emissions slightly increased at an average annual rate of 3.17\% during 1997-2002, sharply increased at an average annual rate of $13.71 \%$ during 2002-2006, and then increased at an average annual rate of 5.71\% during 20062010, with a $6.55 \%$ increase during 2010-2012. Combined with Figures 1-3, energy consumption and $\mathrm{CO}_{2}$ emissions had a growing trend since China joined WTO in 2001 and kept a gentle increase tendency because of the global financial crisis in 2008. Overall, China's $\mathrm{CO}_{2}$ emissions rapidly grow at an average annual rate of $7.03 \%$ from 1997 to 2012. It is urgent to control the rapid growth of $\mathrm{CO}_{2}$ emissions, especially to enhance the management level in the manufacturing 
TABLE 3: Annual time series of carbon dioxide emissions in China during 1997-2012.

\begin{tabular}{|c|c|c|c|c|c|c|c|c|}
\hline Year & Excavation & Manufacturing & $\begin{array}{l}\text { Electric power, gas, } \\
\text { and water } \\
\text { production and } \\
\text { supply }\end{array}$ & Agriculture & Construction & $\begin{array}{l}\text { Transportation, } \\
\text { storage, and postal } \\
\text { services }\end{array}$ & $\begin{array}{c}\text { Wholesale retail } \\
\text { trade, and food } \\
\text { services }\end{array}$ & Other \\
\hline 1997 & 312.63 & 1921.08 & 973.50 & 77.14 & 15.68 & 137.05 & 26.12 & 64.82 \\
\hline 1998 & 282.65 & 1831.24 & 965.93 & 78.47 & 20.07 & 152.37 & 28.28 & 59.52 \\
\hline 1999 & 273.86 & 1807.17 & 989.19 & 78.89 & 19.51 & 174.61 & 30.69 & 66.04 \\
\hline 2000 & 340.43 & 2006.27 & 1082.04 & 42.95 & 20.79 & 211.27 & 28.41 & 67.31 \\
\hline 2001 & 339.58 & 2054.86 & 1141.15 & 43.79 & 20.88 & 216.85 & 28.03 & 68.47 \\
\hline 2002 & 327.23 & 2093.60 & 1303.91 & 47.21 & 21.48 & 231.68 & 28.89 & 70.52 \\
\hline 2003 & 401.22 & 2430.96 & 1549.97 & 53.90 & 22.70 & 260.28 & 30.71 & 75.13 \\
\hline 2004 & 302.95 & 2970.25 & 1778.53 & 65.18 & 26.53 & 309.43 & 34.63 & 88.41 \\
\hline 2005 & 360.40 & 3373.23 & 1971.85 & 73.37 & 29.06 & 347.12 & 39.08 & 87.80 \\
\hline 2006 & 373.27 & 3665.59 & 2231.64 & 75.63 & 31.58 & 383.36 & 41.54 & 93.12 \\
\hline 2007 & 414.58 & 3815.56 & 2452.00 & 71.58 & 31.55 & 415.53 & 44.29 & 101.69 \\
\hline 2008 & 434.65 & 4009.35 & 2493.91 & 67.46 & 29.96 & 429.96 & 41.92 & 102.65 \\
\hline 2009 & 468.05 & 4208.16 & 2644.60 & 69.55 & 32.82 & 442.46 & 47.67 & 104.40 \\
\hline 2010 & 521.82 & 4562.88 & 2764.34 & 74.30 & 37.66 & 485.88 & 49.55 & 113.03 \\
\hline 2011 & 552.50 & 4908.10 & 3109.14 & 77.87 & 39.95 & 528.07 & 55.57 & 124.56 \\
\hline 2012 & 585.31 & 5115.06 & 3174.20 & 80.34 & 39.39 & 586.52 & 60.02 & 133.63 \\
\hline
\end{tabular}

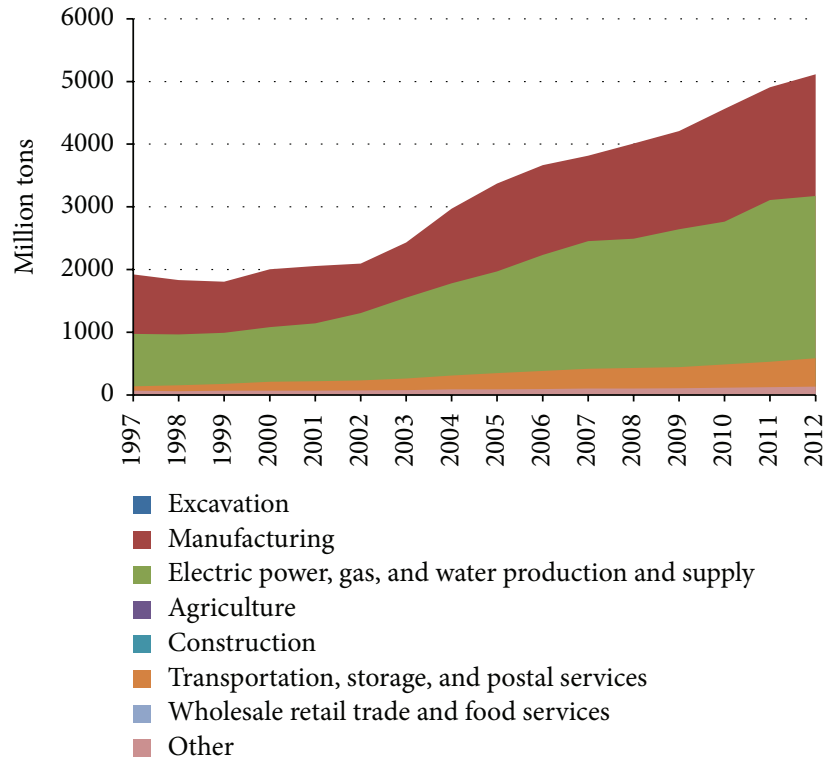

FIGURE 2: Carbon dioxide emissions of different sectors in China from 1997 to 2012.

and electric power, gas, and water production and supply industry.

\section{Factors Decomposition of $\mathrm{CO}_{2}$ Emissions}

4.1. Results of Decomposition. According to IPAT equation and improved LMDI theory [15], carbon dioxide emissions are decomposed into six influential factors, including $\mathrm{CO}_{2}$

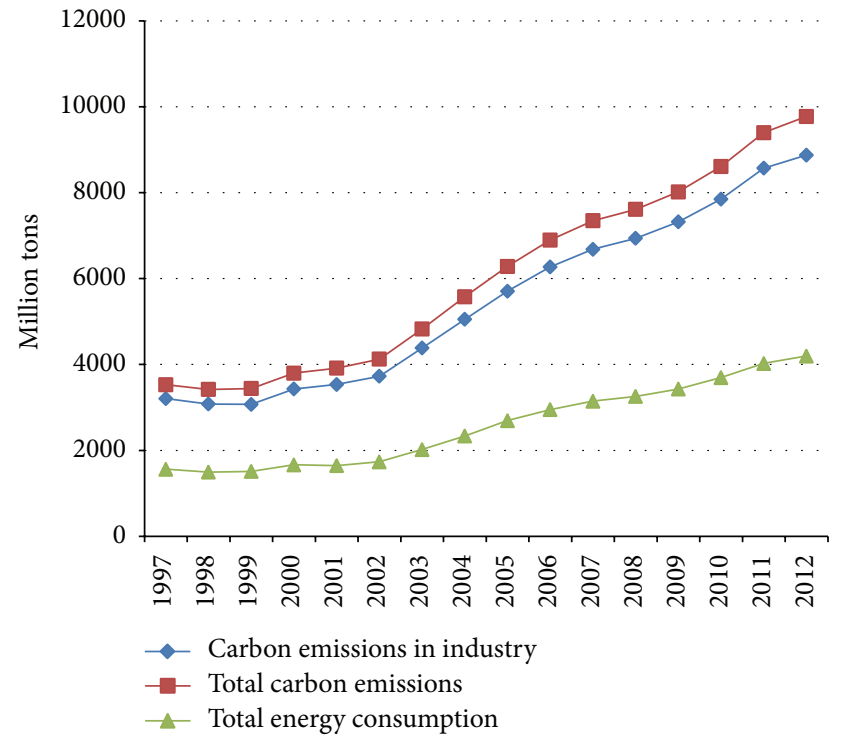

FIGURE 3: Energy consumption and $\mathrm{CO}_{2}$ emissions in China from 1997 to 2012.

emissions intensity effect, energy structure effect, energy intensity effect, industrial structure effect, economic output effect, and population effect; we also figured out the total effect for energy-related $\mathrm{CO}_{2}$ emissions and the contribution value of each effect in China from 1997 to 2012. The results are shown in Tables 4 and 5.

It can be seen from Table 4 that the energy structure effect has negative impact on $\mathrm{CO}_{2}$ emissions every year during 1997-1999 and 2006-2010 and 2001-2002 and 2003-2004 and 
TABLE 4: Annual time series decomposition results from 1997 to 2012 (unit: million tons).

\begin{tabular}{|c|c|c|c|c|c|c|}
\hline Year & Total effect & $\begin{array}{c}\text { Energy structure } \\
\text { effect }\end{array}$ & Energy intensity effect & $\begin{array}{c}\text { industry } \\
\text { structure effect }\end{array}$ & $\begin{array}{c}\text { Economic output } \\
\text { effect }\end{array}$ & Population effect \\
\hline $1997-1998$ & -109.4871 & -1.7313 & -275.6457 & -93.7646 & 228.3628 & 33.2918 \\
\hline 1998-1999 & 21.4415 & -14.0674 & -200.1312 & -16.0364 & 222.0020 & 29.6745 \\
\hline $1999-2000$ & 359.4614 & 0.2811 & 25.1612 & 41.7187 & 263.8472 & 28.4531 \\
\hline $2000-2001$ & 114.1639 & 4.4553 & -150.5583 & -47.1924 & 279.4508 & 28.0084 \\
\hline 2001-2002 & 211.1651 & -4.4379 & -104.3862 & -29.1264 & 322.2080 & 26.9076 \\
\hline $2002-2003$ & 700.3627 & 16.0271 & 171.1570 & 86.8637 & 398.5222 & 27.7928 \\
\hline 2003-2004 & 748.1505 & -3.9766 & 215.8047 & 38.9266 & 466.6497 & 30.7462 \\
\hline 2004-2005 & 705.9677 & 42.1127 & -42.0590 & 71.8748 & 599.2378 & 34.8015 \\
\hline $2005-2006$ & 613.8349 & 4.8132 & -223.0458 & 46.3947 & 748.9156 & 36.7572 \\
\hline 2006-2007 & 451.0658 & -3.2350 & -376.1556 & -111.5281 & 904.8411 & 37.1434 \\
\hline $2007-2008$ & 262.7867 & -9.3576 & 381.5340 & -796.9310 & 649.2422 & 38.2991 \\
\hline 2008-2009 & 407.8675 & -0.2058 & 11.0418 & -291.3561 & 649.5419 & 38.8457 \\
\hline 2009-2010 & 591.6323 & -18.2824 & -130.1869 & -85.3780 & 785.3577 & 40.1220 \\
\hline $2010-2011$ & 786.2802 & 15.8330 & 146.4642 & -175.8375 & 756.7241 & 43.0964 \\
\hline 2011-2012 & 378.7056 & -11.9456 & -52.5474 & -443.0089 & 839.5163 & 46.6913 \\
\hline $1997-2012$ & 6243.3986 & 16.2825 & -603.5531 & -1804.3810 & 8114.4194 & 520.6308 \\
\hline
\end{tabular}

TABLE 5: Annual time series effect coefficient for each contribution value from 1997 to 2012.

\begin{tabular}{|c|c|c|c|c|c|c|}
\hline Year & Total effect & $\begin{array}{c}\text { Energy structure } \\
\text { effect }\end{array}$ & Energy intensity effect & $\begin{array}{c}\text { industry structure } \\
\text { effect }\end{array}$ & $\begin{array}{c}\text { Economic output } \\
\text { effect }\end{array}$ & Population effect \\
\hline 1997-1998 & -0.1730 & -0.0027 & -0.4356 & -0.1482 & 0.3609 & 0.0526 \\
\hline 1998-1999 & 0.0445 & -0.0292 & -0.4153 & -0.0333 & 0.4607 & 0.0616 \\
\hline $1999-2000$ & 1.0000 & 0.0008 & 0.0700 & 0.1161 & 0.7340 & 0.0792 \\
\hline $2000-2001$ & 0.2240 & 0.0087 & -0.2954 & -0.0926 & 0.5483 & 0.0550 \\
\hline 2001-2002 & 0.4335 & -0.0091 & -0.2143 & -0.0598 & 0.6615 & 0.0552 \\
\hline $2002-2003$ & 1.0000 & 0.0229 & 0.2444 & 0.1240 & 0.5690 & 0.0397 \\
\hline $2003-2004$ & 0.9895 & -0.0053 & 0.2854 & 0.0515 & 0.6172 & 0.0407 \\
\hline 2004-2005 & 0.8935 & 0.0533 & -0.0532 & 0.0910 & 0.7584 & 0.0440 \\
\hline 2005-2006 & 0.5791 & 0.0045 & -0.2104 & 0.0438 & 0.7066 & 0.0347 \\
\hline 2006-2007 & 0.3148 & -0.0023 & -0.2625 & -0.0778 & 0.6315 & 0.0259 \\
\hline $2007-2008$ & 0.1401 & -0.0050 & 0.2034 & -0.4249 & 0.3462 & 0.0204 \\
\hline 2008-2009 & 0.4116 & -0.0002 & 0.0111 & -0.2940 & 0.6554 & 0.0392 \\
\hline $2009-2010$ & 0.5585 & -0.0173 & -0.1229 & -0.0806 & 0.7414 & 0.0379 \\
\hline 2010-2011 & 0.6910 & 0.0139 & 0.1287 & -0.1545 & 0.6650 & 0.0379 \\
\hline 2011-2012 & 0.2717 & -0.0086 & -0.0377 & -0.3179 & 0.6024 & 0.0335 \\
\hline 1997-2012 & 7.3788 & 0.0246 & -1.1043 & -1.2573 & 9.0584 & 0.6574 \\
\hline
\end{tabular}

2011-2012, but it has a positive impact during 1999-2001 and 2004-2006 and 2002-2003 and 2010-2011. The energy intensity effect has a negative impact during 1997-1999 and 2000-2002 and 2004-2007 and 2009-2010 and 2011-2012, while the rest of years stay positive. The industry structure effect has negative impact on $\mathrm{CO}_{2}$ emissions every year during 1997-1999 and 2000-2002 and 2006-2012, yet it has a positive one during 2002-2006. The economic output effect and population scale effect play the same roles of positive impact for $\mathrm{CO}_{2}$ emissions during 1997-2012. Figure 4 shows that there are generally the similar trends between effect coefficient of industrial structure and total effect coefficient. Therefore, we can draw a conclusion that the change trend of industrial structure can directly affect the total effect.

As can be seen clearly from Figure 3, the changes of $\mathrm{CO}_{2}$ emissions can be divided into four stages: the first stage (from 1997 to 2002) is that $\mathrm{CO}_{2}$ emissions increases smoothly; the second (from 2002 to 2006) is that $\mathrm{CO}_{2}$ emissions raises high speed; the third (from 2006 to 2010) is the slow growth of $\mathrm{CO}_{2}$ emissions; the final session (from 2010 to 2012) involves the large scale rise of $\mathrm{CO}_{2}$ emissions year by year. This paper made a more specific decomposition on four stages and 
TABLE 6: Various stages of decomposition effect based on LMDI during 1997-2012.

\begin{tabular}{|c|c|c|c|c|}
\hline Year & 1997-2002 & $2002-2006$ & $2006-2010$ & 2010-2012 \\
\hline \multicolumn{5}{|l|}{ Contribution value } \\
\hline$\Delta C_{M}$ & -15.5004 & 58.9763 & -31.0808 & 3.8874 \\
\hline$\Delta C_{R}$ & -705.5600 & 121.8569 & -113.7667 & 93.9168 \\
\hline$\Delta C_{H}$ & -144.4011 & 244.0598 & -1285.1932 & -618.8465 \\
\hline$\Delta C_{Y}$ & 1315.8709 & 2213.3253 & 2988.9829 & 1596.2404 \\
\hline$\Delta C_{P}$ & 146.3353 & 130.0976 & 154.4102 & 89.7877 \\
\hline \multicolumn{5}{|l|}{ Significant factors } \\
\hline$M$ & 0.0260 & 0.0213 & 0.0181 & 0.0033 \\
\hline$R$ & 1.1823 & 0.0440 & 0.0664 & 0.0806 \\
\hline$H$ & 0.2420 & 0.0882 & 0.7501 & 0.5312 \\
\hline$Y$ & 2.2051 & 0.7995 & 1.7445 & 1.3702 \\
\hline$P$ & 0.2452 & 0.0470 & 0.0901 & 0.0771 \\
\hline \multicolumn{5}{|l|}{ Effect coefficient } \\
\hline$M$ & -0.0260 & 0.0213 & -0.0181 & 0.0033 \\
\hline$R$ & -1.1823 & 0.0440 & -0.0664 & 0.0806 \\
\hline$H$ & -0.2420 & 0.0882 & -0.7501 & -0.5312 \\
\hline$Y$ & 2.2051 & 0.7995 & 1.7445 & 1.3702 \\
\hline$P$ & 0.2452 & 0.0470 & 0.0901 & 0.0771 \\
\hline The most significant positive effect & $Y$ & Y & $Y$ & $Y$ \\
\hline The most significant negative effect & $R$ & $\mathrm{NO}$ & $H$ & $H$ \\
\hline
\end{tabular}

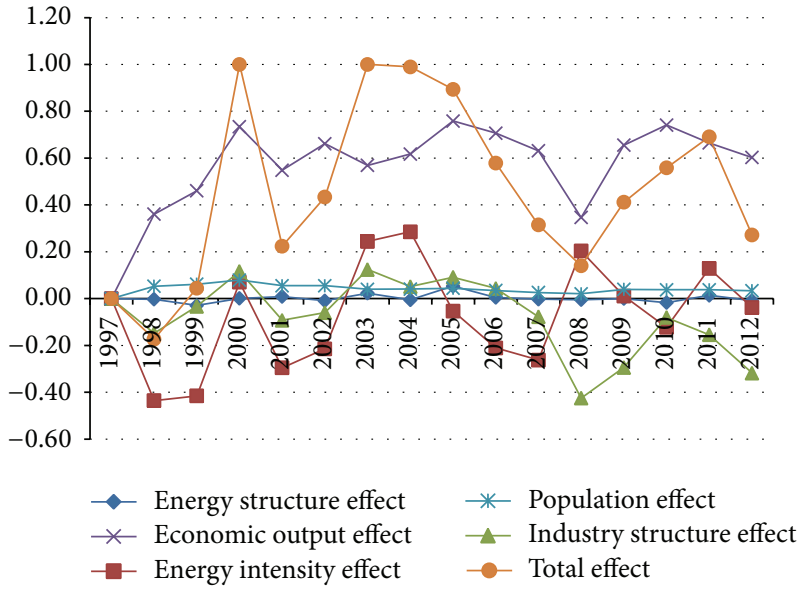

FIGURE 4: Effect coefficients of each contribution value from 1997 to 2012.

obtained the most significant positive effect and the most negative effect of each stage. The decomposition results are as shown in Table 6.

As seen from Table 6, the most significant positive effect of each stage is always the economic output effect (per capita GDP). In recent years, the most significant negative effect is the industrial structure effect in all stages. However, the national government does not pay enough attention to the industry structure effect. If we intend to reduce $\mathrm{CO}_{2}$ emissions dramatically, we should strengthen the adjustment of industrial structure.
4.2. Energy Structure Effect. The energy structure means the pose and proportion of the primary energy and secondary energy in the total output or consumption of energy. The amount of carbon emissions from fossil fuels is different based on the IPCC in 2006 [35]. This paper took the lower limit value of emission factors, respectively, from coal, oil, and natural gas for reference, such that coal was $94600 \mathrm{KG} / \mathrm{TJ}$, oil was $73300 \mathrm{KG} / \mathrm{TJ}$, and natural gas was $56100 \mathrm{KG} / \mathrm{TJ}$. At the same time providing the same heat, carbon emissions from three types of fuel are not identical and we can know carbon emissions from coal are 1.29 and 1.69 times higher than oil and natural gas, relatively. Therefore, energy structure has a great impact on carbon emissions in case of having the same heat.

Figure 5 announces that energy structure effect is roughly in line with the trend of effect coefficient. Two stages where energy structure effect has negative impact on $\mathrm{CO}_{2}$ emissions during 1997-2000 and 2006-2012 restrain the increase of carbon emissions. From Figure 3, $\mathrm{CO}_{2}$ emissions keep smoothly moving in the two stages. As seen from Figure 6, coal is the main source of energy consumption, followed by oil and natural gas. Moreover, the trend upon yearly changes of coal consumption is very consistent with the trend of energy structure effect. This illustrates that the ratio of coal consumption directly affects carbon emissions, with other factors almost remaining unchanged. Since China joined WTO in 2001, the rapid development of economy promotes energy consumption, especially a large number of coal consumption during the period of 2004-2005. As shown in Figure 5, the obvious fluctuation from the coefficient of energy structure effect also intensified the growth of $\mathrm{CO}_{2}$ 


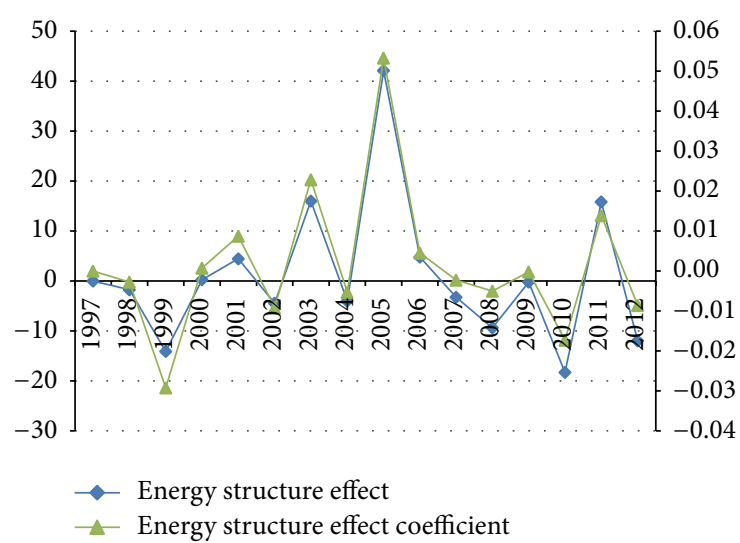

FIGURE 5: Energy structure effect and effect coefficient for carbon dioxide emissions in China during 1997-2012.

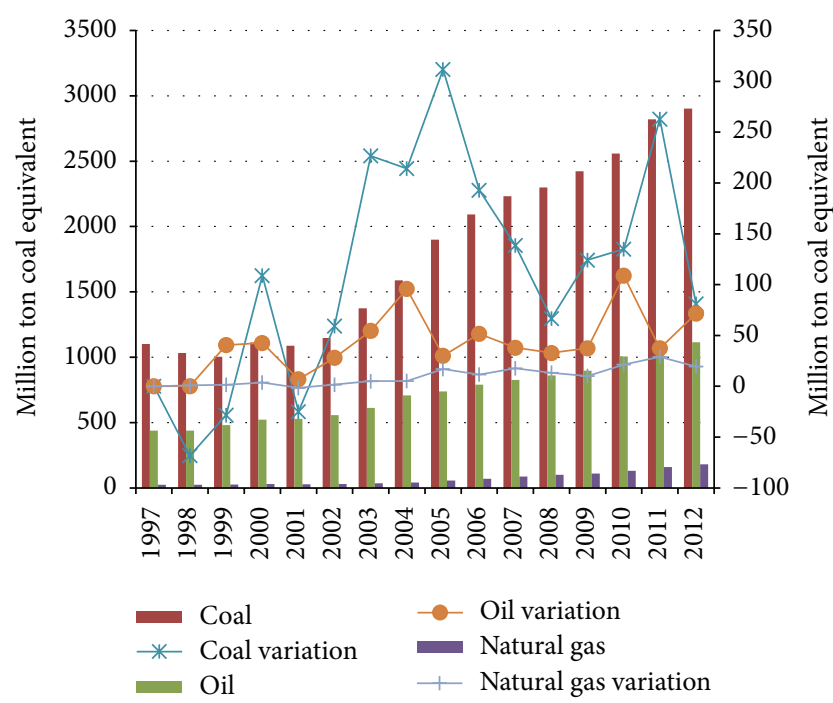

FIGURE 6: Consumption of coal, oil and natural gas, and the change quantity during 1997-2012.

emissions. Coal consumption drastically reduced due to the impact of the financial crisis of 2008, and China's energy structure still focused on coal. In recent years, although the use of hydropower and other renewable energy sources has increased, the proportion of coal consumption in the energy structure is still too high.

4.3. Energy Intensity Effect. Energy intensity refers to the ratio of energy utilization and economic output reflects economic benefits from energy utilization. Energy intensity in this paper refers to the ratio of energy consumption in each sector and economic output in each sector. The higher the energy intensity, the more the carbon emission of per unit GDP. Energy intensity is a uniform metric of the input-output property of the energy structure in units of energy per unit of GDP and exhibits the level of efficiency from energy and economic behavior. Ideally, there is a powerful conception to see the decrease of energy intensity as a symbol of the

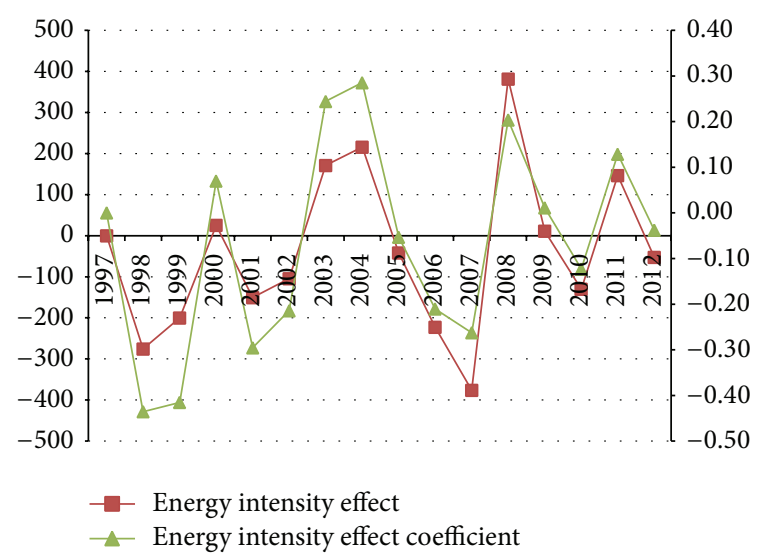

FIGURE 7: Energy intensity effect and effect coefficient for carbon dioxide emissions in China during 1997-2012.

improvement of energy efficiency, which is usually caused by technological advance. The reduction of energy intensity will have a negative impact on carbon emissions on condition that other factors maintain unchanged.

In Figure 7, the trend of energy intensity effect is basically consistent with the trend of effect coefficient. The energy intensity effect had a negative influence on carbon emissions during 1997-1999 and 2000-2002 and 2004-2007 and 20092010 and 2011-2012, with the opposite during the rest of years. Energy intensity effect can cause the inhibition of carbon emissions. Energy consumption sharply increased with the rapid development of economy after joining WTO; energy intensity effect would, of course, rise, gradually increasing the positive impact, and then become a positive driving force of carbon emissions. The fluctuation of energy intensity effect coefficients at the same stage illustrates that the share of energy intensity effect is also increasing. Over the next few years, the state has already begun to put a tighter lid on its efficiency of energy utilization, and energy intensity effect falls subsequently, having been in inhibition.

4.4. Industrial Structure Effect. Industrial structure refers to the proportion of economic output in each sector accounted for GDP. As seen from Table 1, the decomposed results in this research illustrate that industrial structure effect is the uppermost negative driving force to carbon emissions. According to the previous literatures [24-27], it is not strange that it has not been noticed by policymakers before, since the inhibitory effects of industrial structure on $\mathrm{CO}_{2}$ emissions are not so obvious. From the analysis data of research in the paper, that is mostly because industrial structure effect has been the negative driving force during 2006-2012, especially during the period of 2010-2012 (from 2010 to 2011 is -175.8375 and from 2011 to 2012 is -443.0089 ), we can see that industrial structure effect to a large extent restrains the growth of $\mathrm{CO}_{2}$ emissions. As shown in Figure 8, due to the impact of global financial crisis of 2008, there was a sharp decline in industrial structure effect and effect coefficient also dropped significantly. The inhibitory effect on $\mathrm{CO}_{2}$ emissions this moment is very obvious and the proportion is up to $40 \%$. 
TABLE 7: Department decomposition results of industrial structure effect from 1997 to 2012.

\begin{tabular}{|c|c|c|c|c|c|}
\hline Sector & 1997-2012 & 1997-2002 & $2002-2006$ & $2006-2010$ & 2010-2012 \\
\hline Excavation & 59.28 & -17.36 & 28.06 & -28.32 & 76.89 \\
\hline Manufacturing & -301.59 & -108.29 & 185.24 & -55.09 & -323.45 \\
\hline Electric power, gas, and water production and supply & -1502.79 & -57.94 & 71.32 & -1130.58 & -385.60 \\
\hline Agriculture & -38.64 & -17.55 & -14.26 & -6.82 & 0.00 \\
\hline Construction & 5.83 & -1.76 & 1.83 & 4.60 & 1.16 \\
\hline Transportation, storage, and postal services & -65.78 & 28.94 & -28.27 & -71.89 & 5.45 \\
\hline Wholesale retail trade, and food services & 6.89 & 1.58 & -2.35 & 4.54 & 3.10 \\
\hline Other & 32.42 & 27.96 & 2.49 & -1.63 & 3.60 \\
\hline Total industrial structure effect & -1804.38 & -144.40 & 244.06 & -1285.19 & -618.85 \\
\hline
\end{tabular}

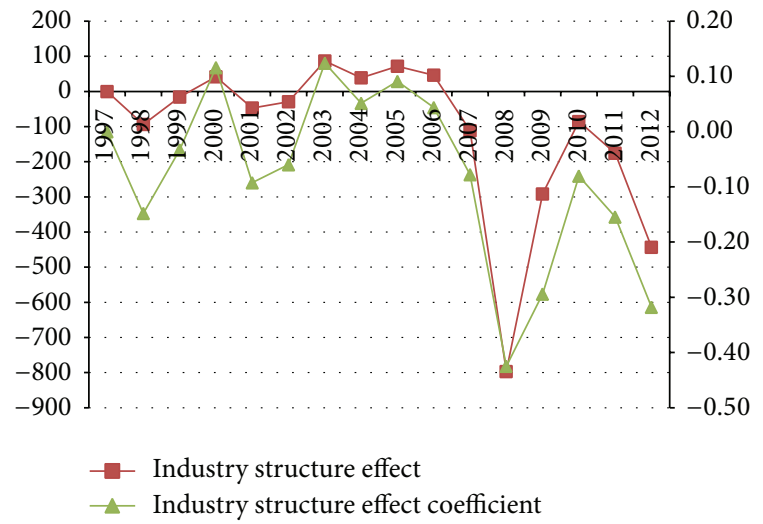

FIGURE 8: Industrial structure effect and effect coefficient for carbon dioxide emissions in China during 1997-2012.

The adjustment strength on industrial structure from state continuously strengthens in recent years. There is a further decomposition on different stages of industrial structure effect in different industries from 1997 to 2012 from Table 7 and it is gained that the most significant inhibition impacts on Chinas $\mathrm{CO}_{2}$ emissions in every stage are manufacturing sector and electric power, gas, and water production and supply sector. The reason why industrial structure effect has prominent negative impact is that the specific weight of economic output in manufacturing and electric power, gas, and water production and supply sectors over the national GDP is decreasing. Government should properly adjust the economic output in manufacturing and electric power, gas, and water production and supply sectors to effectively control carbon emissions.

4.5. Economic Output Effect. Economic output effect called per capita GDP reflects the social average living standards and macroeconomic performance. As for the developing countries, carbon emission caused by consumption patterns is higher when per capita GDP is higher. It is an effective tool to understand and grasp the macroeconomic performance of a country or region. It mirrors both the growth of economy and quality of life of much of the world's population. Energy is the key ingredient, which stands by economic development. Conversely, energy consumption rises thanks

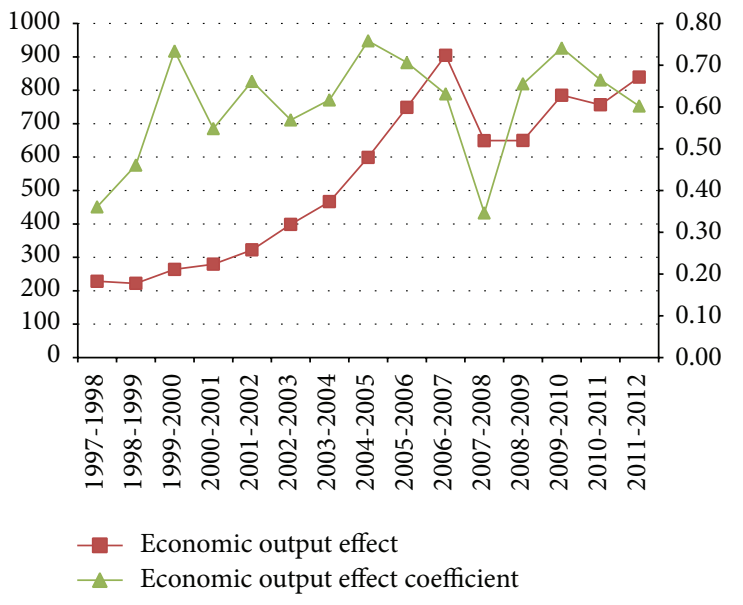

FIGURE 9: Economic output effect and effect coefficient for carbon dioxide emissions in China during 1997-2012.

to the rapid urbanization and industrialization, and so does carbon emission. In general, carbon emissions and economic development are closely bound up. From Table 4, the per capita GDP is the supreme positive driving factor to $\mathrm{CO}_{2}$ emissions during 1997-2012. As analyzed from Figure 9, economic output effect had been rising from 1997 to 2007, peaked in 2007, and started to fall subsequently. Owing to the global financial crisis of 2008, it basically maintained mild in the period from 2008 to 2009 and broadly remained flat for the period from 2007 to 2008 . However, the effect coefficient of economic output has a significant increase compared to the last year. This illustrates that all the effects being affected by the global financial crisis lead to the addition in the proportion of per capita GDP over total effects. During 19972012, the national GDP (from 7225.34 to 29533.57 billion Yuan) is raised at an average annual rate of 9.84\%. Meanwhile, per capita GDP was enhanced at an average annual rate of $9.16 \%$. The growth of per capita GDP led directly to the buildup of carbon emissions. Accordingly, economic output is one of the significant factors that should be considered to take an array of down-to-earth measures to cut carbon emissions.

4.6. Population Scale Effect. Population scale effect refers to the influence of demographic shifts on carbon emissions. 


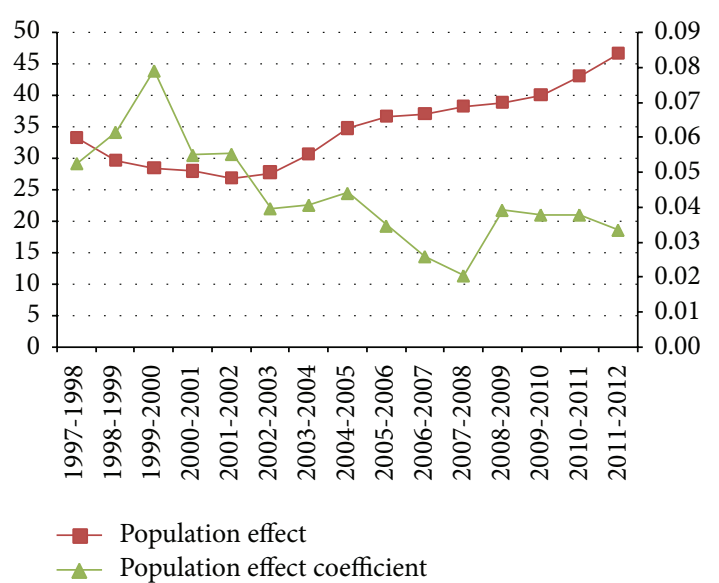

Figure 10: Population scale effect and effect coefficient for carbon dioxide emissions in China during 1997-2012.

With the accelerated progress of urbanization, a substantial increase in carbon emissions results from the dramatic growth of the city population.

Table 4 reveals that the population scale effect plays a positive role on $\mathrm{CO}_{2}$ emissions, and we can see that carbon emissions will grow if population increases. The increase in population associated with the urbanization which is the significant factor of the massive cement demand in big cities and traffic infrastructure construction can set off the growing carbon emissions. On the other hand, energy consumption caused by accretion of population might promote carbon emissions as well. Figure 10 reveals that population effect has maintained an upward trend since 2011, while the population effect coefficient has been in a downward trend. The results illustrate that the share of population effect is coming down. Nevertheless, thanks to the impact of the financial crisis, the contribution value of each effect has a drop while the share of population effect has risen.

This paper counts the aggregate contribution of each effect on $\mathrm{CO}_{2}$ emissions during 1997-2012 on the basis of factor decomposition of LMDI. As a whole, economic output effect, population effect, and energy structure effect are positive driving forces on $\mathrm{CO}_{2}$ emissions; and energy intensity effect and industrial structure effects have done just the opposite. As shown in Figure 11, the economic output effect (share of contribution is $129.97 \%$ ) has a primary positive impact on $\mathrm{CO}_{2}$ emissions, with the impact of population effect $(8.34 \%)$ and energy structure effect $(0.26 \%)$ being in the next place. We are not fully aware that we can tinker up energy structure which is the cardinal inhibiting element contributing $-28.90 \%$ to debase $\mathrm{CO}_{2}$ emissions. The energy intensity effect plays the part of inhibitory action with the contribution value of $-9.67 \%$.

\section{Summaries and Policy Applications}

5.1. Summaries. This research aims at ascertaining the cardinal element affecting $\mathrm{CO}_{2}$ emissions in China to furnish a succession of down-to-earth policies with the low-carbon

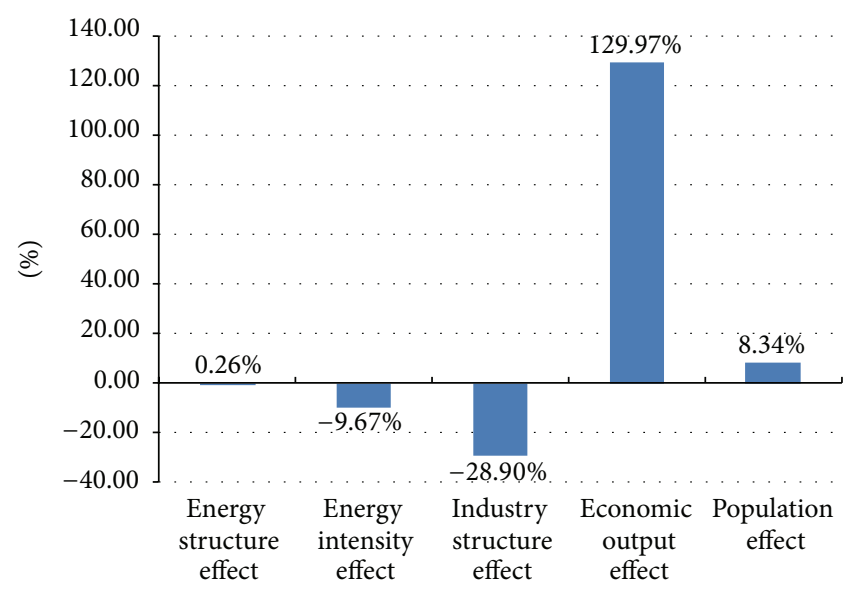

FIgURE 11: The contribution of different effects to carbon emissions in China during 1997-2012.

economy concerned. The energy-related $\mathrm{CO}_{2}$ emissions are resolved into energy structure, energy intensity, industrial structure, economic output, and population scale effects. We seek in depth the elements affecting China's carbon dioxide emissions from diverse industries and multiple kinds of fossil fuels. This paper has a more rounded strategy compared with the most existing decomposition of China when it comes to diverse industries and multiple kinds of fossil fuels in China in particular. The decomposed results are summarized as follows.

(1) This paper fosters a new weight determination method by drawing "contribution value-significant factor-effect coefficient" and applies effect coefficient of each contribution value to character the size of relative effect on carbon emissions. Furthermore, we make further efforts to divide up the most significant positive effect and the most negative effect of four years period. As acquired from the research, the most significant positive effect has always been economic output effect from 1997 to 2012. The most significant negative effect in recent years is the industrial structure effect. This method provides the comprehensive and intuitive analyses of the factors affecting carbon dioxide emissions and it is more convenient for the government to furnish a succession of down-to-earth policies and targeted policy shift.

(2) The total energy consumption increased at an average annual rate of $6.80 \%$ and $\mathrm{CO}_{2}$ emissions raised at an average annual rate of 7.03\% during 1997-2012. The ratio of coal over the total energy consumption gently reduced from $70.39 \%$ to $69.12 \%$, the proportion of oil decreased from $28.07 \%$ to $26.58 \%$, and the ratio of natural gas sharply increased from $1.58 \%$ to $4.32 \%$. Despite the fact that the consumption of natural gas accounts for the proportion increases year by year, coal consumption has been the cardinal energy consumption. 
(3) Through the empirical analysis, it is informed that there exists coherent tendency between industrial $\mathrm{CO}_{2}$ emissions and the total $\mathrm{CO}_{2}$ emissions, by and large. The supreme origin of China's carbon emissions is industry, in which manufacturing and electric power, gas, and water production and supply are the sectors above the average of energy consumption. Manufacturing is the largest department of $\mathrm{CO}_{2}$ emissions accounting for more than 50\%, followed by electric power, gas, and water production and supply sector with $30 \%$; the last is excavation with $5 \%$. Generally speaking, carbon emissions are largely caused by energy consumption in industry. During 1997-2012, the share of coal consumption changed from $85.12 \%$ to $87.81 \%$ in industry, the ratio of coal consumption in manufacturing varied from $79.12 \%$ to $77.51 \%$, while the ratio in electric power, gas, and water production and supply sector was modified from $96.91 \%$ to $99.82 \%$.

(4) As a whole, economic output possesses the significant positive impact on carbon emissions, and population effect and energy structure effect followed. Xu et al. stated that economic output effect with the contribution of $159.41 \%$ was shown to be the cardinal driving force, and population effect (5.51\%) and energy structure effect (2.64\%) followed. On the contrary, the energy intensity effect acted as the key constraining force with $-61.52 \%$, and the industrial structure effect with $-6.04 \%$ followed [32]. Our empirical study emphasizes that economic output effect is shown to be the cardinal driving force in China's $\mathrm{CO}_{2}$ emissions with $129.97 \%$, and population effect with $8.34 \%$ and energy structure effect with $0.26 \%$ followed. The industrial structure acts as a master brake on China's $\mathrm{CO}_{2}$ emissions contributing $-28.90 \%$, whose potential has not been explored for the moment, even if energy intensity effect $(-9.67 \%)$ holds a certain degree of inhibition impact on $\mathrm{CO}_{2}$ emissions. Compared with the previous studies, the reason why industrial structure effect possesses the prominent inhibitions on $\mathrm{CO}_{2}$ emissions is that the state strengthens the supervision of industrial production in recent years. The specific weight of economic output in manufacturing and electric power, gas, and water production and supply sectors over GDP drops significantly. Therefore, the government ought to carry out an army of measures to manipulate carbon emissions.

5.2. Policy Applications. At present, an ocean of vital sectors still relies heavily on the low price of energy in China. The approach of low-carbon economy prefers to draw attention to other facets rather than transform the energy structure. A round of targeted steps should be drawn up to boost the goal of "energy intensity could lessen 16\%" in the 12th FiveYear Plan Outline and the target of "China aims to cut carbon emissions per unit of GDP by $40-45 \%$ at the level of 2005 by 2020." Accordingly, we put forward the following tips.
The first and foremost, it is gained that coal is the largest origin of energy consumption based on the carbon emissions coefficients from Intergovernmental Panel on Climate Change (IPCC) [35]. The long-term circumstance will hold the line in virtue of the trait of energy structure in China and the high share of coal consumption. In addition, carbon emissions would absolutely augment as a result of the industrialization and urbanization. Since coal has always been and will remain as the uppermost origin of energy consumption, one of the top-drawer elements to minify carbon emissions is energy substitution. An array of lesspolluting energy which contained certain renewable energy such as wind or sunlight or tidal energy, natural gas, and nuclear power could be applied taking the place of coal to dominate emissions. The country ought to strengthen the degree of the development of new energy and develop the technology of both high energy-efficient and clean fuel energy. It is a vital avenue for disposing energy crisis and cutting down the carbon emissions caused by fossil energy consumption to capitalize on renewable energy in China.

There is one more point; according to the results from this research, energy intensity effect is an inhibitory factor. Accordingly, we should reduce the energy intensity and improve energy utilization efficiency. China ought to transform the pattern of economic growth and capture its attention to both the quantity and the quality of its growth to boost shift from extensive economy to intensive. China ought to regard the development of light industry whose energy intensity has a relatively low level and products with higher margins as allimportant task. On the other hand, China ought to speed up weeding out the laggard production processes and facility to arouse industrial technological innovation.

The last but not the least, China ought to adjust and optimize the industrial structure to cut down the share of industry over the national economy and quicken the development of the tertiary industry. In the paper, industrial structure effect plays the crucial negative part on $\mathrm{CO}_{2}$ emissions. The government should put the greatest emphasis on economic output of manufacturing sector and electric power, gas, and water production and supply sector. China is obliged to expedite the step of industrial structure which needs to be adjusted, enhance scientific input, and focus on high-technology industries to effectively depress carbon emissions.

\section{Conflict of Interests}

The authors declare that there is no conflict of interests.

\section{Acknowledgments}

This study is supported by the National Natural Science Foundation of China (NSFC) (71471061), the Fundamental Research Funds for the Central Universities (Project ID 2014ZP11), and Philosophy and Social Science Research Base of Hebei Province. 


\section{References}

[1] P. Stigson, E. Dotzauer, and J. Yan, "Improving policy making through government-industry policy learning: the case of a novel Swedish policy framework," Applied Energy, vol. 86, no. 4, pp. 399-406, 2009.

[2] National Bureau of Statistics of the People's Republic of China, Statistical Yearbook of the People's Republic of China, 2012, http://www.stats.gov.cn/tjsj/Ndsj/2012/indexch.htm.

[3] P. R. Ehrlich and J. P. Holdren, "Impact of population growth," Science, vol. 171, no. 3977, pp. 1212-1217, 1971.

[4] P. R. Ehrlich and J. P. Holdren, "One-dimensional economy," Bulletin of the Atomic Scientists, vol. 28, no. 5, pp. 16-27, 1972.

[5] N. Nakicenovic, "Socioeconomic driving forces of emissions scenarios," in The Global Carbon Cycle: Integrating Humans, Climate, and the Natural World, C. B. Field and M. R. Raupach, Eds., pp. 225-239, Island Press, New York, NY, USA, 2004.

[6] D. Guan, K. Hubacek, C. L. Weber, G. P. Peters, and D. M. Reiner, "The drivers of Chinese $\mathrm{CO}_{2}$ emissions from 1980 to 2030," Global Environmental Change, vol. 18, no. 4, pp. 626-634, 2008.

[7] G. P. Peters, C. L. Weber, D. Guan, and K. Hubacek, "China's growing $\mathrm{CO}_{2}$ emissions-a race between increasing consumption and efficiency gains," Environmental Science and Technology, vol. 41, no. 17, pp. 5939-5944, 2007.

[8] Y. Wang, H. Y. Zhao, L. Y. Li, Z. Liu, and S. Liang, "Carbon dioxide emission drivers for a typical metropolis using inputoutput structural decomposition analysis," Energy Policy, vol. 58, pp. 312-318, 2013.

[9] K. Feng, Y. L. Siu, D. Guan, and K. Hubacek, "Analyzing drivers of regional carbon dioxide emissions for China: a structural decomposition analysis," Journal of Industrial Ecology, vol. 16, no. 4, pp. 600-611, 2012.

[10] M. Xu, R. Li, J. C. Crittenden, and Y. Chen, " $\mathrm{CO}_{2}$ emissions embodied in China's exports from 2002 to 2008: a structural decomposition analysis," Energy Policy, vol. 39, no. 11, pp. 73817388, 2011.

[11] H. Du, J. Guo, G. Mao, A. M. Smith, X. Wang, and Y. Wang, " $\mathrm{CO}_{2}$ emissions embodied in China-US trade: input-output analysis based on the emergy/dollar ratio," Energy Policy, vol. 39, no. 10, pp. 5980-5987, 2011.

[12] B. W. Ang, "The LMDI approach to decomposition analysis: a practical guide," Energy Policy, vol. 33, no. 7, pp. 867-871, 2005.

[13] B. W. Ang and F. Q. Zhang, "Inter-regional comparisons of energy-related $\mathrm{CO}_{2}$ emissions using the decomposition technique," Energy, vol. 24, no. 4, pp. 297-305, 1999.

[14] B. W. Ang and F. Q. Zhang, "A survey of index decomposition analysis in energy and environmental studies," Energy, vol. 25, no. 12, pp. 1149-1176, 2000.

[15] B. W. Ang, F. Q. Zhang, and K.-H. Choi, "Factorizing changes in energy and environmental indicators through decomposition," Energy, vol. 23, no. 6, pp. 489-495, 1998.

[16] C. Wang, J. Chen, and J. Zou, "Decomposition of energy-related $\mathrm{CO}_{2}$ emission in China: 1957-2000," Energy, vol. 30, no. 1, pp. 73-83, 2005.

[17] C. Ma and D. I. Stern, "China's changing energy intensity trend: a decomposition analysis," Energy Economics, vol. 30, no. 3, pp. 1037-1053, 2008.

[18] G. Ipek Tunç, S. Türüt-Aşik, and E. Akbostanci, "A decomposition analysis of $\mathrm{CO}_{2}$ emissions from energy use: Turkish case," Energy Policy, vol. 37, no. 11, pp. 4689-4699, 2009.
[19] C. Sheinbaum, L. Ozawa, and D. Castillo, "Using logarithmic mean Divisia index to analyze changes in energy use and carbon dioxide emissions in Mexico's iron and steel industry," Energy Economics, vol. 32, no. 6, pp. 1337-1344, 2010.

[20] S. Paul and R. N. Bhattacharya, " $\mathrm{CO}_{2}$ emission from energy use in India: a decomposition analysis," Energy Policy, vol. 32, no. 5, pp. 585-593, 2004.

[21] J. W. Sun, "An analysis of the difference in $\mathrm{CO}_{2}$ emission intensity between Finland and Sweden," Energy, vol. 25, no. 11, pp. 1139-1146, 2000.

[22] K.-H. Choi and B. W. Ang, "A time-series analysis of energyrelated carbon emissions in Korea," Energy Policy, vol. 29, no. 13, pp. 1155-1161, 2001.

[23] G. Ipek Tunç, S. Türüt-Aşik, and E. Akbostanci, "A decomposition analysis of $\mathrm{CO}_{2}$ emissions from energy use: turkish case," Energy Policy, vol. 37, no. 11, pp. 4689-4699, 2009.

[24] J.-H. Xu, T. Fleiter, W. Eichhammer, and Y. Fan, "Energy consumption and $\mathrm{CO}_{2}$ emissions in China's cement industry: a perspective from LMDI decomposition analysis," Energy Policy, vol. 50, pp. 821-832, 2012.

[25] M. Zhang, X. Liu, W. Wang, and M. Zhou, "Decomposition analysis of $\mathrm{CO}_{2}$ emissions from electricity generation in China," Energy Policy, vol. 52, pp. 159-165, 2013.

[26] X. Zhao, N. Li, and C. Ma, "Residential energy consumption in urban China: a decomposition analysis," Energy Policy, vol. 41, pp. 644-653, 2012.

[27] Y. Zhang, J. Zhang, Z. Yang, and S. Li, "Regional differences in the factors that influence China's energy-related carbon emissions, and potential mitigation strategies," Energy Policy, vol. 39, no. 12, pp. 7712-7718, 2011.

[28] S. S. Wang, D. Q. Zhou, P. Zhou, and Q. W. Wang, " $\mathrm{CO}_{2}$ emissions, energy consumption and economic growth in China: a panel data analysis," Energy Policy, vol. 39, no. 9, pp. 48704875, 2011.

[29] F. Wu, L. W. Fan, P. Zhou, and D. Q. Zhou, "Industrial energy efficiency with $\mathrm{CO}_{2}$ emissions in China: a nonparametric analysis," Energy Policy, vol. 49, pp. 164-172, 2012.

[30] W. Li and Q.-X. Ou, "Decomposition of China's carbon emissions intensity from 1995 to 2010: an extended Kaya identity," Mathematical Problems in Engineering, vol. 2013, Article ID 973074, 7 pages, 2013.

[31] L.-C. Liu, Y. Fan, G. Wu, and Y.-M. Wei, "Using LMDI method to analyze the change of China's industrial $\mathrm{CO}_{2}$ emissions from final fuel use: an empirical analysis," Energy Policy, vol. 35, no. 11, pp. 5892-5900, 2007.

[32] S.-C. Xu, Z.-X. He, and R.-Y. Long, "Factors that influence carbon emissions due to energy consumption in China: decomposition analysis using LMDI," Applied Energy, vol. 127, pp. 182193, 2014.

[33] Y. M. Wei, L. C. Liu, Y. Fan, and G. Wu, China Energy Report: $\mathrm{CO}_{2}$ Emissions Research, Science Press, Beijing, China, 2008.

[34] L. B. Wu, S. J. Kaneko, and S. J. Matsuoka, "Driving forces behind the stagnancy of China's energy-related $\mathrm{CO}_{2}$ emissions from 1996 to 1999: the relative importance of structural change, intensity change and scale change," Energy Policy, vol. 33, no. 3, pp. 319-335, 2005.

[35] IPCC, Intergovernmental Panel on Climate Change Guidelines for National Greenhouse Gas Inventories, OECD, Paris, France, 1999. 


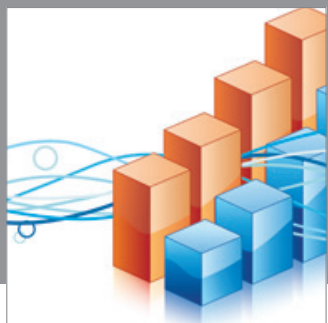

Advances in

Operations Research

mansans

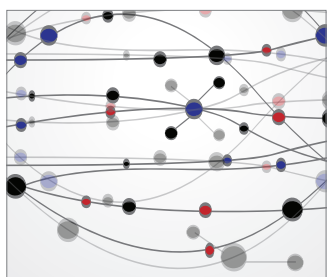

The Scientific World Journal
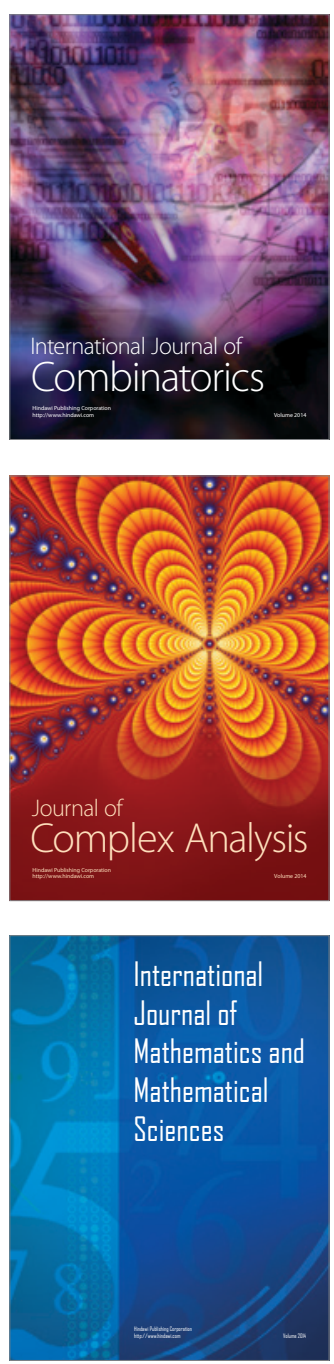
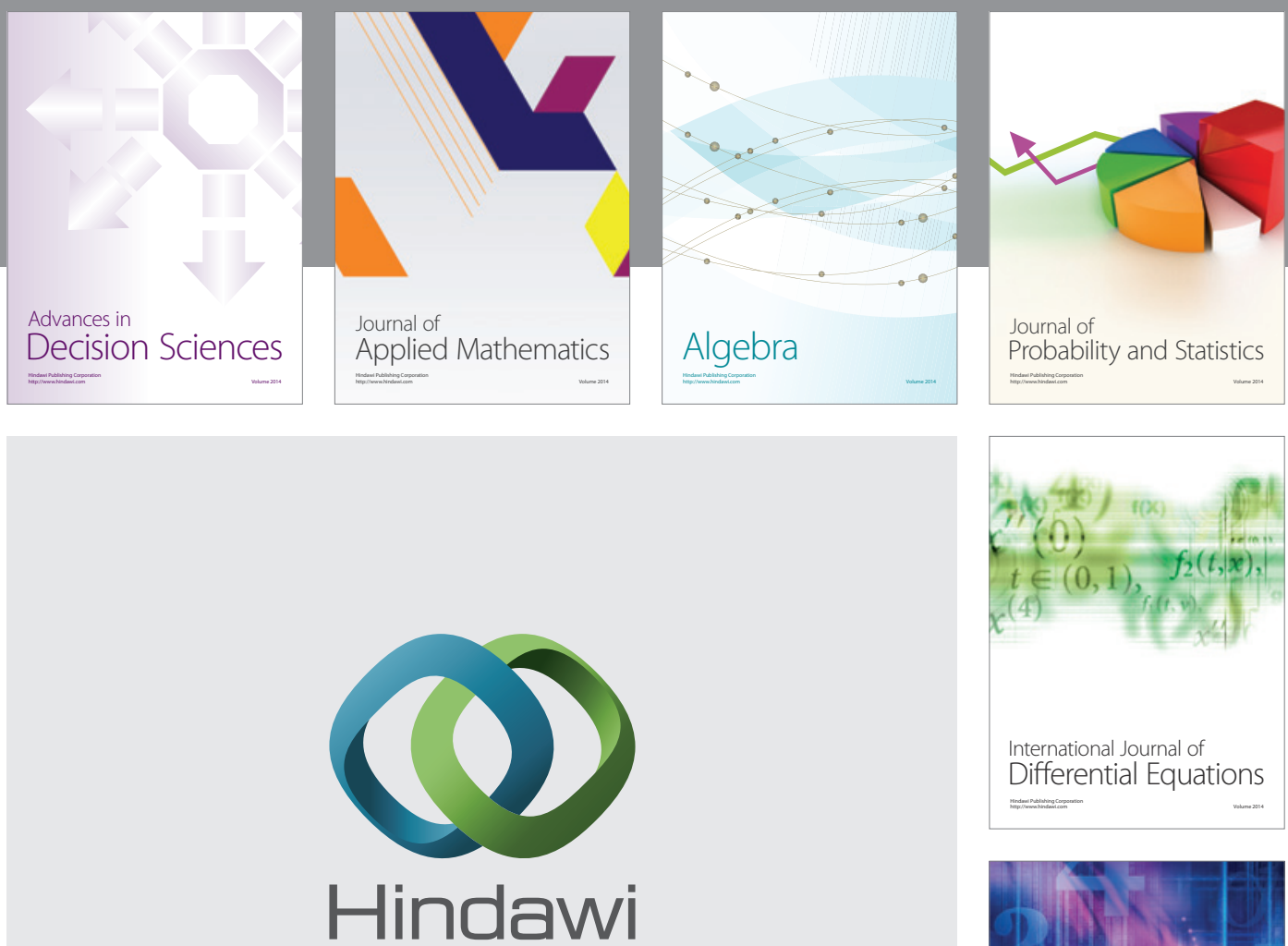

Submit your manuscripts at http://www.hindawi.com
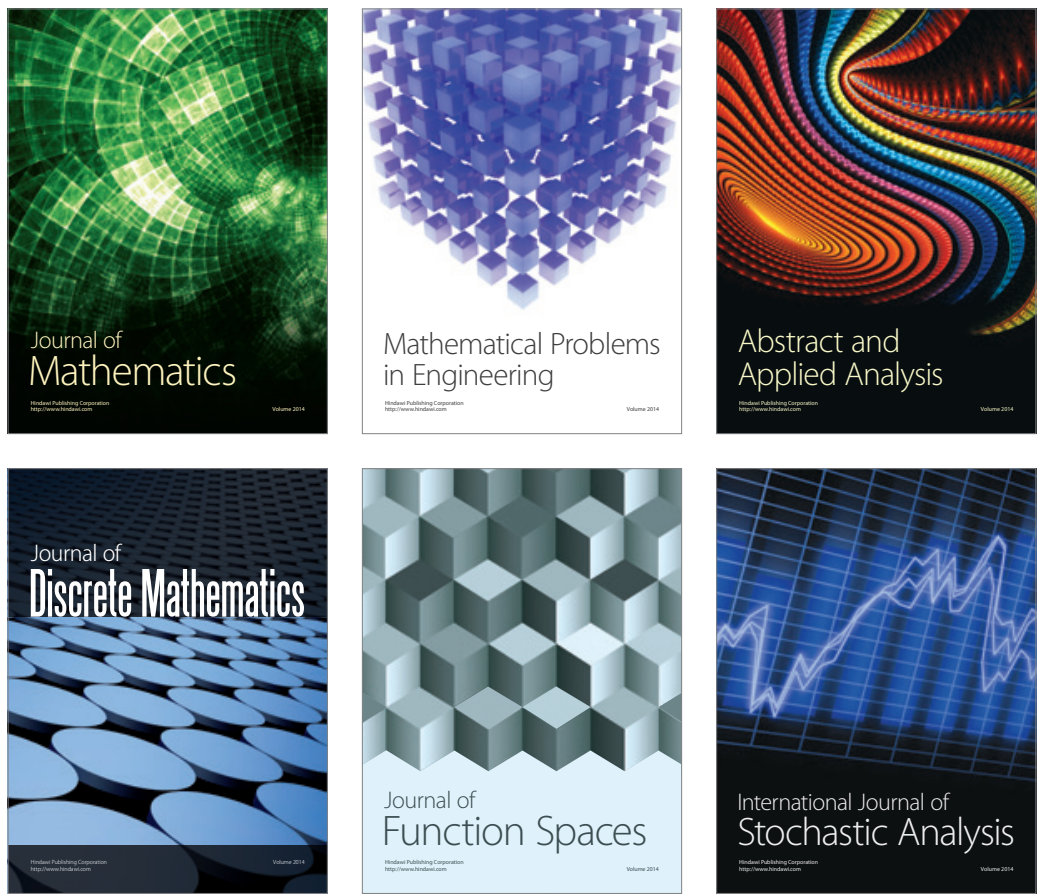

Journal of

Function Spaces

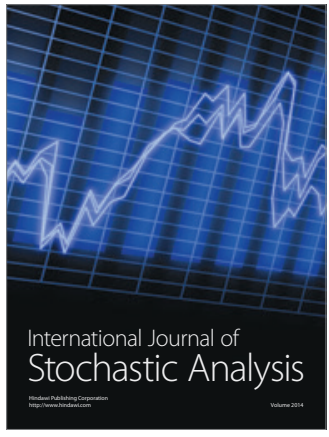

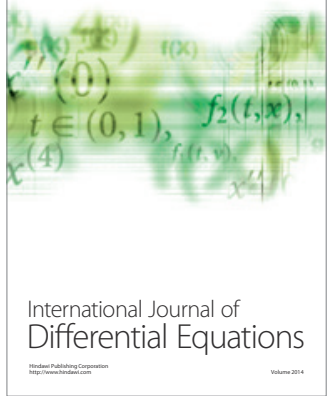
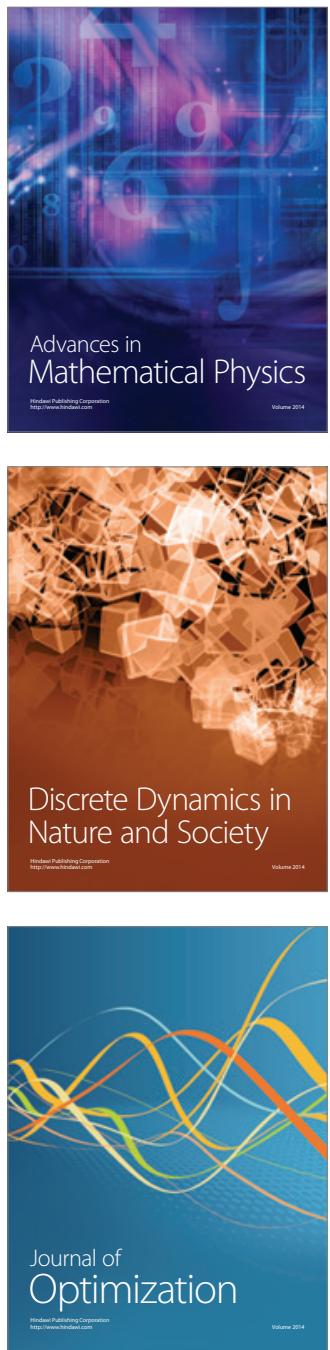